\title{
Environmental Enhancement Through Use of Recycled Aggregate Concrete in a Two-Stage Mixing Approach
}

\author{
Vivian W. Y. Tam ${ }^{1}$, X. F. Gao ${ }^{2}$, and C. M. Tam ${ }^{3}$ \\ ${ }^{1}$ Lecturer, School of Engineering, Gold Coast Campus, Griffith University PMB50, Gold Coast \\ Mail Centre, Qld 9726, Australia \\ ${ }^{2}$ Professor, Faculty of Science, Xi' an Jiaotong University, Xi'an, 710049, P. R. China \\ ${ }^{3}$ Professor, Department of Building and Construction, City University of Hong Kong, 83 Tat \\ Chee Road, Kowloon Tong, Hong Kong SAR, P. R. China \\ Correspondence Author: Prof. C. M. Tam, Department of Building and Construction, City \\ University of Hong Kong, 83 Tat Chee Road, Kowloon Tong, Hong Kong. (Tel: +852-2784- \\ 4377; Fax: +852-2788-7612; E-mail: bctam@cityu.edu.hk)
}

Running Head: Recycled Aggregate Concrete for Environmental Enhancement 


\section{ABSTRACT}

As a high priority of waste management and recycling by the Hong Kong government, Recycled Aggregate (RA) has been used in various construction applications, mainly as subgrade, roadwork, and unbound materials. However, higher-grade applications are rare. The major barrier encountered is the variation of quality within RA, which causes lower strength, resulted from crystallization of Recycled Aggregate Concrete (RAC). Therefore, the objective of this study is to examine the crystallization of RAC in a Two-Stage Mixing Approach. Following are the five areas of interest: i) investigate the waste problems in construction activities; ii) examine the crystal development on the hydration of cement paste; iii) develop a two-stage mixing approach (TSMA) for improving the performance of RAC; iv) explore the crystallization of TSMA in comparison with the Normal Mixing Approach (NMA) through use of Differential Scanning Calorimetry (DSC); and v) verify the results obtained from DSC analysis with those obtained from compressive strength testing. This study adopted 0, 20, and 100\% RA substitution in virgin aggregate and measured by DSC and compressive strength on both TSMA and NMA. TSMA uses only half the water for mixing, forming a thin layer of cement slurry on the surface of RA that will permeate into the porous old cement mortar and fill old cracks and voids in the pre-mix process. The results from DSC analysis clearly demonstrated that TSMA can give a better crystallization of $\mathrm{CaO} \cdot \mathrm{SiO}_{2} \cdot \mathrm{H}_{2} \mathrm{O}[\mathrm{CSH}]$ and $\mathrm{Ca}(\mathrm{OH})_{2}[\mathrm{CH}]$. The optimal situation occurs on $20 \%$ RA substitution in virgin aggregate, balancing the advantages of each, a finding supported by the results from compressive strength testing. Therefore, TSMA is a superior methodology and open a wider application for the use of RAC.

Key Words: crystallization, differential scanning calorimetry, recycled aggregate, concrete, construction. 


\section{INTRODUCTION}

Construction wastes are considered as having major impacts on the environment. Waste is defined as the by-product generated and removed from construction, renovation, and demolition of workplaces or sites of building and civil engineering structures (Cheung 1993). With the demands to implement major infrastructure projects in Hong Kong, together with many commercial building and housing redevelopment programmes, a large amount of construction waste is being produced. Extra construction materials are usually planned due to the lack of consideration given to waste reduction during the planning and design stages in order to minimize the generation of wastes. The excessive wastage of raw materials, improper waste management, and low awareness of the need for waste reduction are common in the local construction industry.

Although the reuse of concrete waste as Recycled Aggregate (RA) can reduce the consumption of limited resources and thereby save construction costs, the use of RA also has shortcomings, e.g., weaker interfacial behaviour between aggregate and cement paste, higher portions of cement mortar attached and lower quality. (Alexander 1996; Covertry 1999; Farran 1956; Jia et al. 1986; Kawano 2000; Keru and Jianhua 1988; Li et al. 2001; Popovics 1987; Tomosawa and Noguchi 2000; Xueqan et al. 1988). In order to facilitate waste management through the use of RA, it is vital to investigate ways in which its shortcomings can be mitigated.

\section{OBJECTIVE}

The research objective is to examine the crystallization of Recycled Aggregate Concrete (RAC) for use in a two-stage mixing approach (TSMA). The following are focal issues:

i) Investigate the waste problems in construction activities,

ii) Examine the crystal development on the hydration of cement paste,

iii) Develop a TSMA for improving the performance of RAC,

iv) Explore the crystallization for TSMA in comparison with that in the Normal Mixing Approach (NMA) through application of Differential Scanning Calorimetry (DSC), and

v) Verify the results obtained from DSC analysis with those from compressive strength testing. 


\section{CRYSTALLIZATION}

At the micro-structural level, Hardened Cement Paste (HCP) is an intimate but inhomogeneous mixture of a variety of crystalline and quasi-crystalline phases and pores of different sizes and shapes (see Figure 1). Four major compounds: tricalcium silicate $\left[3 \mathrm{CaO} \cdot \mathrm{SiO}_{2}\right.$ or $\mathrm{C}_{3} \mathrm{~S}$ ], dicalcium silicate $\left[2 \mathrm{CaO} \cdot \mathrm{SiO}_{2}\right.$ or $\mathrm{C}_{2} \mathrm{~S}$ ], tricalcium aluminate $\left[3 \mathrm{CaO} \cdot \mathrm{Al}_{2} \mathrm{O}_{3}\right.$ or $\left.\mathrm{C}_{3} \mathrm{~A}\right]$ and telracalcium aluminoferrite $\left[4 \mathrm{CaO} \cdot \mathrm{Al}_{2} \mathrm{O}_{3} \cdot \mathrm{Fe}_{2} \mathrm{O}_{3}\right.$ or $\left.\mathrm{C}_{4} \mathrm{AF}\right]$ occur in ordinary Portland cement (Sha et al. 1999).

In concrete, most of the volume is calcium silicate hydrate $\left[\mathrm{CaO} \cdot \mathrm{SiO}_{2} \cdot \mathrm{H}_{2} \mathrm{O}\right.$, abbreviated as $\mathrm{CSH}]$, the principal hydration product, which is a highly disordered crystalline material of variable composition. Upon the addition of water, $\mathrm{C}_{3} \mathrm{~S}$ rapidly reacts to release calcium ions, hydroxide ions, and a large amount of heat. The $\mathrm{pH}$ quickly rises to greater than 12 because of the release of alkaline hydroxide $\left(\mathrm{OH}^{-}\right)$ions. This initial hydrolysis slows quickly after it starts, resulting in a decrease in heat evolved. The reaction continues slowly and produces calcium and hydroxide ions until the system becomes saturated. Once this occurs, the calcium hydroxide $\left[\mathrm{Ca}(\mathrm{OH})_{2}\right.$, abbreviated as $\left.\mathrm{CH}\right]$ starts to crystallize. Simultaneously, $\mathrm{CSH}$ begins to form. Ions precipitate out of solution, which accelerates the reaction of $\mathrm{C}_{3} \mathrm{~S}$ to calcium and hydroxide ions. The evolution of heat is then dramatically increased. The formations of $\mathrm{CH}$ and $\mathrm{CSH}$ crystals provide 'seeds' upon which more CSH can form. The CSH crystals grow thicker making it more difficult for water molecules to reach the unhydrated $\mathrm{C}_{3} \mathrm{~S}$. The speed of the reaction is now controlled by the rate at which water molecules diffuse through the $\mathrm{CSH}$ coating. This coating thickens over time, causing the production of CSH to become slower and slower. The molecular structure of CSH is layered and provides for a very high internal porosity. The process of the hydration of $\mathrm{C}_{3} \mathrm{~S}$ is given as Equation (1) (MAST 2004). $\mathrm{C}_{2} \mathrm{~S}$ also affects the strength of concrete through its hydration. $\mathrm{C}_{2} \mathrm{~S}$ reacts with water in a similar manner compared to $\mathrm{C}_{3} \mathrm{~S}$, but much more slowly. The heat released is less then that by the hydration of $\mathrm{C}_{3} \mathrm{~S}$ because the $\mathrm{C}_{2} \mathrm{~S}$ is much less reactive. The process of the hydration of $\mathrm{C}_{2} \mathrm{~S}$ is given as Equation (2) (MAST 2004):

$$
\begin{aligned}
& 2 \mathrm{Ca}_{3} \mathrm{SiO}_{5}+7 \mathrm{H}_{2} \mathrm{O} \rightarrow 3 \mathrm{CaO} \cdot 2 \mathrm{SiO}_{2} \cdot 4 \mathrm{H}_{2} \mathrm{O}+3 \mathrm{Ca}(\mathrm{OH})_{2} \\
& 2 \mathrm{Ca}_{2} \mathrm{SiO}_{4}+5 \mathrm{H}_{2} \mathrm{O} \rightarrow 3 \mathrm{CaO} .2 \mathrm{SiO}_{2} \cdot 4 \mathrm{H}_{2} \mathrm{O}+\mathrm{Ca}(\mathrm{OH})_{2}
\end{aligned}
$$

In contrast to $\mathrm{CSH}, \mathrm{Ca}(\mathrm{OH})_{2}[\mathrm{CH}]$, also known as Portlandite, is highly crystalline and has a fixed composition, which comprises more than $20 \%$ of the hydration products in a fully cured cement paste (Bhatty 1991). CH appears as thin hexagonal platelets, often layered; typically tens 
of $\mu \mathrm{m}$ across (see Figure 2). With continued hydration, they grow massive, lose their hexagonal outline, and encapsulate other regions of the paste (Ahmed and Struble 1995). Massive blocks of $\mathrm{CH}$ crystals can be easily identified in mature pastes. Unhydrated residues of clinker grains, which are crystalline in nature, are present even in well-hydrated systems. They are produced by the hydration of the silicate phases, $\mathrm{C}_{3} \mathrm{~S}, \mathrm{C}_{2} \mathrm{~S}$, and free lime [CaO] as shown in Equations (3) to (5) (Bhatty 1991; John et al. 1998; Lea and Desch 1935). It can be seem from Equations (3) and (4) that weight for the hydration of $\mathrm{C}_{3} \mathrm{~S}$ [Equation (3)] produces three times the amount of $\mathrm{CH}$ as does the hydration of $\mathrm{C}_{2} \mathrm{~S}$ [Equation (4)]. Thus the ratio of these two phases will affect the amount of $\mathrm{CH}$ formed.

$$
\begin{array}{cc}
2\left(3 \mathrm{CaO} . \mathrm{SiO}_{2}\right)+6 \mathrm{H}_{2} \mathrm{O} \rightarrow 3 \mathrm{CaO} .2 \mathrm{SiO}_{2} .3 \mathrm{H}_{2} \mathrm{O}+3 \mathrm{Ca}(\mathrm{OH})_{2} & \text { Eqn. (3) } \\
2\left(3 \mathrm{CaO} . \mathrm{SiO}_{2}\right)+4 \mathrm{H}_{2} \mathrm{O} \rightarrow 3 \mathrm{CaO} .2 \mathrm{SiO}_{2} \cdot 3 \mathrm{H}_{2} \mathrm{O}+\mathrm{Ca}(\mathrm{OH})_{2} & \text { Eqn. (4) } \\
\mathrm{CaO}+\mathrm{H}_{2} \mathrm{O} \rightarrow \mathrm{Ca}(\mathrm{OH})_{2} & \text { Eqn. (5) } \\
6 \mathrm{Ca}^{2+}+2 \mathrm{Al}(\mathrm{OH})_{4-}+4 \mathrm{OH}^{-}+3 \mathrm{SO}_{4}{ }^{2-}+26 \mathrm{H}_{2} \mathrm{O} \rightarrow \mathrm{Ca}_{6}\left[\mathrm{Al}(\mathrm{OH})_{6}\right]_{2}\left(\mathrm{SO}_{4}\right)_{3} .26 \mathrm{H}_{2} \mathrm{O} & \text { Eqn. (6) } \\
\text { Another type of crystal commonly found in } \mathrm{HCP} \text { is ettringite }\left[\mathrm{Ca}_{6}\left[\mathrm{Al}(\mathrm{OH})_{6}\right]_{2}\left(\mathrm{SO}_{4}\right)_{3} .26 \mathrm{H}_{2} \mathrm{O}\right],
\end{array}
$$
as reacted in Equation (6) (see Figure 3). Where ettringite is observed in cracks and voids, it appears as needles that have a distinctive low birefringence and low refractive index; it is often found in conjunction with CH (John et al. 1998). Situations such as movement of water through concrete or the formation of alkali-silica gel appear capable of causing conditions that allow it to reform. In old concrete, these deposits can be massive. However, as the ettringite is reformed in void spaces, its expansion can be accommodated (John et al. 1998). Ettringite is produced by a reaction that requires an excess of the sulphate ion $\mathrm{SO}_{4}{ }^{2-}$ over the aluminate phase in the pore solution (John et al. 1998). As hardening proceeds, more of the aluminate phase moves into the pore solution, which converts the ettringite to mono-calcium sulfo-aluminate $\left[\mathrm{CaSO}_{4} \cdot 2 \mathrm{CaO} \cdot \mathrm{Al}_{2} \mathrm{O}_{3} \cdot 12 \mathrm{H}_{2} \mathrm{O}\right]$. This conversion results in a small decrease in volume and thus may occur in the hardened paste without damage. Both ettringite and monocalcium sulfoaluminate hydrate formed during setting and hardening are usually submicroscopic and require the use of Scanning Electron Microscopy (SEM) observations. Only where ettringite is secondary and reformed from reactions of the $\mathrm{SO}_{4}{ }^{2-}$ ion with monocalcium sulfo-aluminate do its crystals become large enough to be observed in thin-section. Localized concentrations of ettringite are controlled by both the amount of water and space at particle surfaces, with 
crystallization modified by the surface texture and porosity of the aggregate, which greatly improves the strength (John et al. 1998).

\section{MATERIALS AND METHODS}

The weaknesses of RA, which include high porosity, high amounts of cracks, high levels of sulphate and chloride content, high levels of impurity, and high cement mortar remains, will affect the mechanical performance of RAC (Ryu 2002). The prerequisite in applying RA to high grade concrete is to overcome these weaknesses.

A new mixing approach, the Two-Stage Mixing Approach (TSMA), is proposed as a means to mitigate the weakness of RA. In the normal mixing approach (NMA), the mixer is first charged with about one-half coarse aggregate, then mixed with fine aggregate, then with cement, and finally with the remaining coarse aggregate. Water is then added immediately before the rotation of the drum or starting the pan (Hong Kong Government 1990). TSMA divides the mixing process into two parts and proportionally splits the required water into two streams, which are added at different times. The TSMA mixing procedure is illustrated in Figure 4, while Table 1 shows the symbols used in the figure.

In order to study the crystallization of RAC, experimental work was undertaken by use of Differential Scanning Calorimetry (DSC) [Seiko Instruments (SII) SSC 5200 TG/DTA 220] (Bhatty 1991). The development of crystallization during the TSMA with RA replacement in virgin aggregate of 0,20 , and $100 \%$ was studied. The RA was collected from the Tuen Mun Area 38 centralized recycling plant. Before collection of samples from the cube, the first 4 to $5 \mathrm{~mm}$ of the surface was removed by either grinding or filing. These samples were placed in a small and flat container in shallow pans, with the aim of making a good thermal contact between sample, pan, and heat flux plate (Anasys 2004). The samples weighted approximately $10 \mathrm{mg}$ and were collected from cubes stored under water at about $20^{\circ} \mathrm{C}$ for 28 -day or 56 -day curing. The samples were heated to $600^{\circ} \mathrm{C}$ at a constant heating rate of $20^{\circ} \mathrm{C}$ per minute in a dynamic helium atmosphere.

This experiment was also measured and compared with results from compressive strength testing. The average of three results of measurement with $100 \mathrm{~mm}$ sized cubes was derived according to BS 1881: Part 116 (1983).

\section{RESULTS}


Listed in Table 2 are the results of DSC analysis, which show the major endothermic peaks and their quantification after 28-day and 56-day curing, and the results of the compressive strength testing are tabulated in Table 3.

DSC analysis showed there are two major peaks, peaks 1 and 2, at around $90^{\circ} \mathrm{C}$ and $450^{\circ} \mathrm{C}$, respectively (Poon and Wong 2004; Sha et al. 1999). The first endothermic peak, peak 1, is the result of dehydration reactions due to the loss of water from $\mathrm{CSH}$, which reduce cohesive forces between CSH layers and where coarsening of pores starts. The second major peak, peak 2, corresponds to the dehydroxylation of $\mathrm{CH}$, in which the decomposition of $\mathrm{CH}$ starts from $350^{\circ} \mathrm{C}$ to $500^{\circ} \mathrm{C}$. A smaller peak is also found in the DSC's curves at around $140^{\circ} \mathrm{C}$ to $215^{\circ} \mathrm{C}$. This endothermic peak is attributed as ettringite, which corresponds to the hydration products of $\mathrm{C}_{3} \mathrm{~A}$ (Sha et al. 1999). A typical DSC curve is shown in Figure 5.

\section{DISCUSSION AND VERIFICATION}

In the general sense, it was found that the more RA substituted in the concrete, the poorer the quality of the concrete. This is because the cohesive force between aggregate and cement paste is weaker in RA than that in virgin aggregate (John et al. 1998). This situation is also reflected from the DSC's results; both the quantities of CSH and $\mathrm{CH}$ recorded are lowered with increased in amounts of RA substitution for NMA. For example, the peak area of CSH with $0 \%$ RA substitution after 28-day curing is $21.85 \mu \mathrm{V}^{\circ} \mathrm{C}$; while that of 20 and $100 \%$ RA substitution are $18.38 \mu \mathrm{V}^{\circ} \mathrm{C}$ and $12.97 \mu \mathrm{V}^{\circ} \mathrm{C}$, respectively (see Table 2). Similar situations are also recorded on the peak area of $\mathrm{CH}$ and in the curing conditions of 56-day. It is also proved from the results obtained from compressive strength testing after 28-day curing at 55.72 $\mathrm{MPa}, 53.68 \mathrm{Mpa}$, and $51.72 \mathrm{MPa}$ for 0,20 , and $100 \%$ RA substitution, respectively (see Table 3 ).

Although the pessimistic situations happened when substituting RA with virgin aggregate, TSMA helps solve the current problem. From the results of DSC analysis, the crystallization of $\mathrm{CSH}$ and $\mathrm{CH}$ are enhanced when mixed by TSMA compared with that for NMA. After 28-day curing, dehydroxylation of $\mathrm{CH}$ at $27.35 \mu \mathrm{V}^{\circ} \mathrm{C}, 48.31 \mu \mathrm{V}^{\circ} \mathrm{C}$, and $28.61 \mu \mathrm{V}^{\circ} \mathrm{C}$ and compressive strength at $56.00 \mathrm{MPa}, 65.05 \mathrm{Mpa}$, and 55.56 MPa were found with 0, 20, and 100\% RA substitution, respectively, for TSMA. TSMA therefore provides improvement in comparison with NMA on dehydroxylation of $\mathrm{CH}$ at $25.35 \mu \mathrm{V}^{\circ} \mathrm{C}, 25.30 \mu \mathrm{V}^{\circ} \mathrm{C}$, and $21.23 \mu \mathrm{V}^{\circ} \mathrm{C}$ and compressive strength at $55.72 \mathrm{MPa}, 53.68 \mathrm{Mpa}$, and $51.72 \mathrm{MPa}$, respectively. Figure 6 shows the benefits gained from the use of TSMA. 
It is recorded at $20.45 \mu \mathrm{V}^{\circ} \mathrm{C}$ and $28.61 \mu \mathrm{V}^{\circ} \mathrm{C}$ on the dehydration of $\mathrm{CSH}$ and the dehydroxylation of $\mathrm{CH}$, respectively, for TSMA and strength at $55.56 \mathrm{MPa}$ with $100 \% \mathrm{RA}$ substitution, which achieved better performance than that in the same RA substitution for NMA. It is encouragingly found that the results with $100 \% \mathrm{RA}$ replacement for TSMA are as competitive as the traditional approach with $0 \% \mathrm{RA}$ substitution at $21.85 \mu \mathrm{V}^{\circ} \mathrm{C}$ and $25.35 \mu \mathrm{V}^{\circ} \mathrm{C}$ and 55.72 $\mathrm{MPa}$ for the dehydration of $\mathrm{CSH}$, the dehydroxylation of $\mathrm{CH}$ and the compressive strength at 28 days, respectively.

The optimal situation occurs at 20\% RA substitution in virgin aggregate, in balancing the benefits earned from RA and virgin aggregate, which gained $34.21 \mu \mathrm{V}^{\circ} \mathrm{C}$ and $48.31 \mu \mathrm{V}^{\circ} \mathrm{C}$ for the dehydration of $\mathrm{CSH}$ and the dehydroxylation of $\mathrm{CH}$, respectively, after 28-day curing, and 25.44 $\mu \mathrm{V}^{\circ} \mathrm{C}$ and $44.59 \mu \mathrm{V}^{\circ} \mathrm{C}$, respectively, after 56-day curing. The results from compressive strength testing correspond with the similar conclusions at $65.05 \mathrm{MPa}$ and $72.04 \mathrm{MPa}$ after 28-day and 56-day curing, respectively, with $20 \%$ RA replacement ratio. Furthermore, the crystallization of $20 \%$ RA substitution for TSMA is also proved from the examination of Scanning Electron Microscopy (SEM) in Figures 7and 8. Hence, most studies recommended a limit of 30\% RA replacement in concrete mixing (Kikuchi et al. 1988).

\section{CONCLUSIONS}

To alleviate waste problems from construction and demolition activities, recycling concrete waste as RA provides the greatest benefit to the environment. Due to the variation of quality of RA, higher-grade applications are restricted. The two-stage mixing approach (TSMA) helps solve the current pessimistic situations. The TSMA uses only half of the water for mixing to form a thin layer of cement slurry on the surface of RA, which will permeate into the porous old cement mortar and fill the old cracks and voids in the pre-mix process. Thus, TSMA gained a better crystallization of $\mathrm{CSH}$ and $\mathrm{CH}$. From the results of DSC analysis, it was encouragingly found that the $100 \%$ RA substitution in TSMA can be as competitive as the traditional mixing approach with no substitution of RA. Furthermore, the optimal situation occurs with $20 \%$ RA substitution. These results are in agreement with those measured by compressive strength testing. Therefore, TSMA is a superior methodology and opens up a wider application for recycled aggregate concrete.

\section{ACKNOWLEDGMENTS}


The work described in this paper was fully supported by a grant from the Housing Authority Research Fund of the Hong Kong Special Administrative Region, P.R. China (Project Ref. No. 9460004). 


\section{REFERENCES}

Ahmed A and Struble L. 1995. Effects of microstructure of fracture behaviour of hardened cement paste. Proceedings Microstructure of Cement-Based Systems/Bonding and Interfaces in Cementitious Materials Symposia, pp 99-108. Boston, MA, USA. 28 November - 1 December 1994

Alexander MG. 1996. The Effects of Ageing on the Interfacial Zone in Concrete. Interfacial Transition Zone in Concrete: State-of-the-Art Report, pp 150-74

Anasys. 2004. Homepage. Available at http://www.anasys.co.uk

Bhatty JJ. 1991. A review of the application of thermal analysis to cement-admixture systems. Thermochim Acta 189:313

BS 1881. Part 116: 1983. Method for Determination of Compressive Strength of Concrete Cubes. British Standards Institution, London, UK

Cheung CM. 1993. Guidelines for Reduction of Construction Waste on Building Sites. Hong Kong Polytechnic University and Hong Kong Construction Association, Hong Kong, P.R. China

Coventry S. 1999. The Reclaimed and Recycled Construction Materials Handbook. Construction Industry Research and Information Association, London, UK

Farran J. 1956. Contribution minerlogique a letude de ladherence entre constituents hydrates des cimers et les materiaux enrobes. Revuedes Materiaux de Constructions 490:491-2

Hong Kong Government. 1990. Construction Standard: Testing Concrete. Hong Kong Government, Hong Kong, P.R. China

Jia W, Baoyuan L, Songshan X, et al. 1986. Improvement of paste-aggregate interface by adding silica fume. Proceedings of the $8^{\text {th }}$ International Congress on the Chemistry of Cement, Vol III, pp 460-5

John DA, Poole AW, and Sims I. 1998. Concrete Petrography: A Handbook of Investigative Techniques. John Wiley \& Sons, London, UK and New York, NY, USA

Kawano H. 2000. Barriers for Sustainable Use of Concrete Materials. Concrete Technology for a Sustainable Development in the 21st Century, pp 288-93. E \& FN Spon, London, UK and New York, NY, USA

Keru W and Jianhua Z. 1988. The Influence of the Matrix-Aggregate Bond on the Strength and Brittleness of Concrete. Bonding in Cement Comp. Materials Res Soc 114:29-34 
Kikuchi M, Mukai T, and Koizumi H. 1988. Properties of Concrete Products Containing Recycled Aggregate. Demolition and Reuse of Concrete and Masonry: Reuse of Demolition Waste, pp 595-604. Chapman and Hall, London, UK

Lea FM and Desch CH. 1935. The Chemistry of Cement and Concrete. Edward Arnold, London, UK

Li G, Xie H, and Xiong G. 2001. Transition zone studies of new-to-old concrete with different binders. CC\&C 23(4-5):381-7

MAST (Materials Science and Technology): 2004. Homepage. Available at http://matse1.mse.uiuc.edu

Poon CS and Wong YL. 2004. Hardened properties of self-compacting concrete Prepared with rejected fly ash: Before and after exposure to elevated temperature. American Concrete Institute Chine Chapter Inaugural Symposium: Challenges in Concrete Technology, 20 July 2004, American Concrete Institute, American Concrete Institute China Chapter, Professional Development Research Limited, pp 1-19

Popovics S. 1987. Attempts to improve the bond between cement paste and aggregate. Mats \& Stru 20(115):32-8

Ryu JS. 2002. An experimental study on the effect of recycled aggregate on concrete properties. Mag of Conc Res 54(1):7-12

Sha W, O’Neill EA, and Guo Z. 1999. Differential scanning calorimetry study of ordinary Portland cement. C\&CR 29(9):1487-9

Tomosawa F and Noguchi T. 2000. New Technology for the Recycling of Concrete - Japanese Experience. Concrete Technology for a Sustainable Development in the 21st century, pp 274-87. E \& FN Spon, London, UK, and Neww York, UK, USA

Xueqan W, Dongxu L, Qinghan B, et al. 1987. Preliminary study of a composite process in concrete manufacture. C\&CR 17(5):709-14 


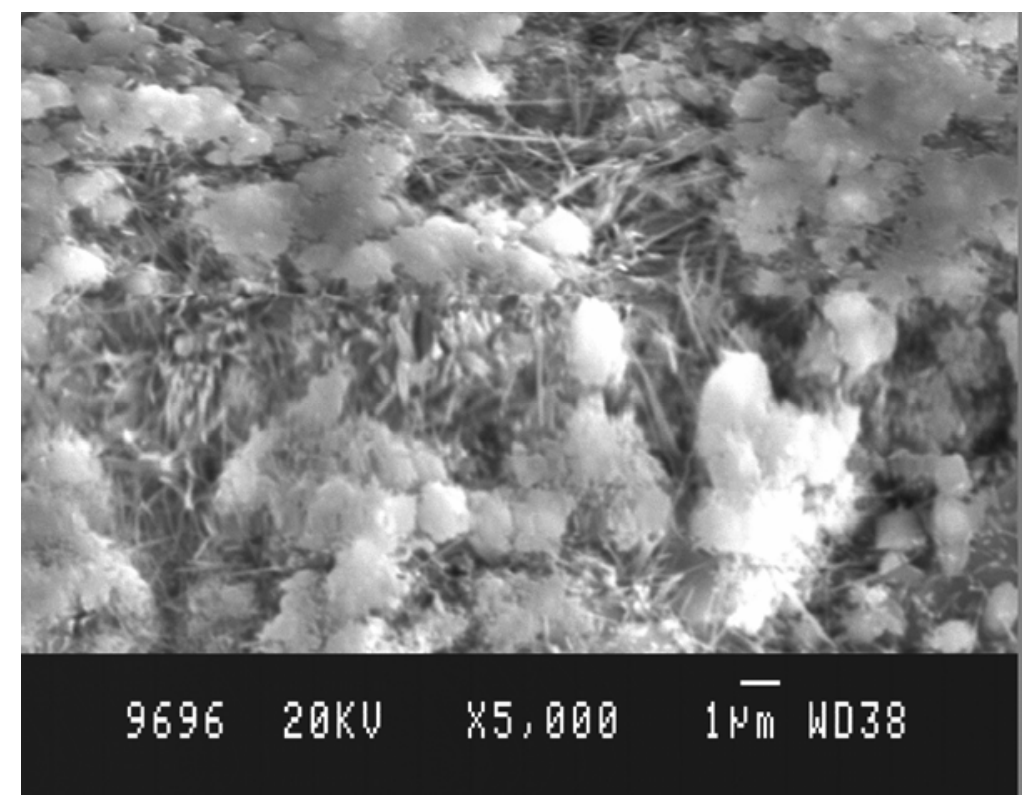

Figure 1. SEM micrograph of the hardened cement paste. 


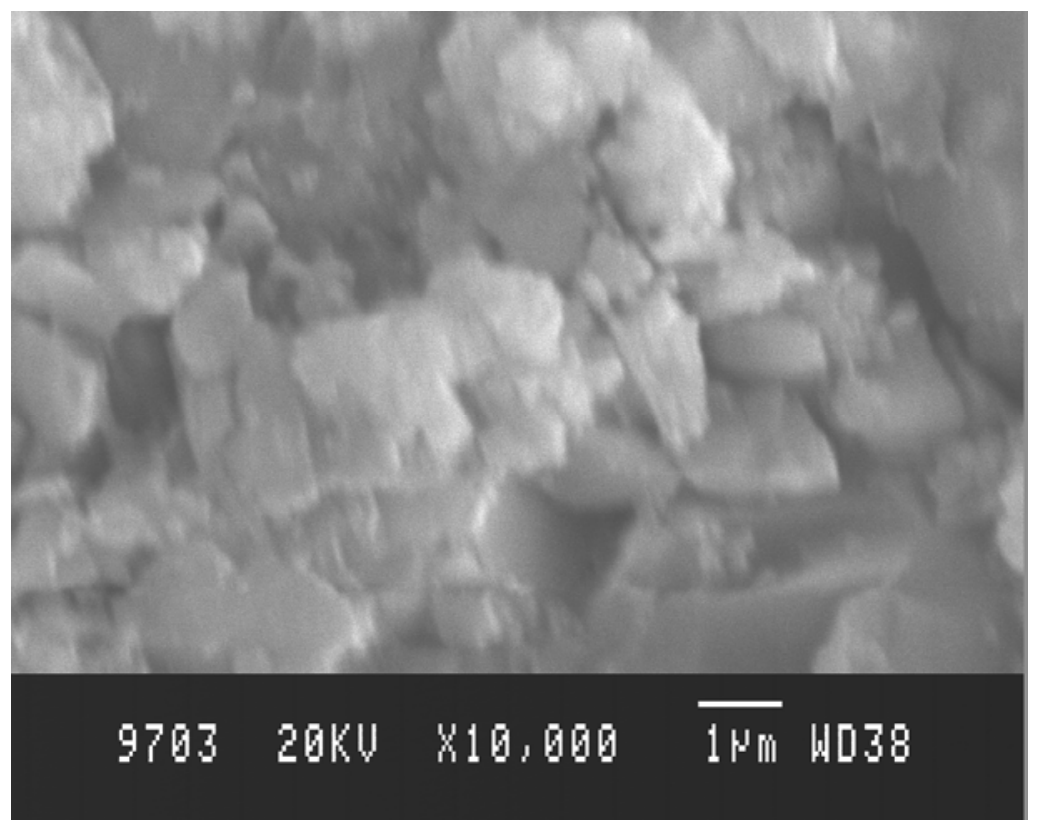

Figure 2. SEM micrograph of calcium hydroxide. 


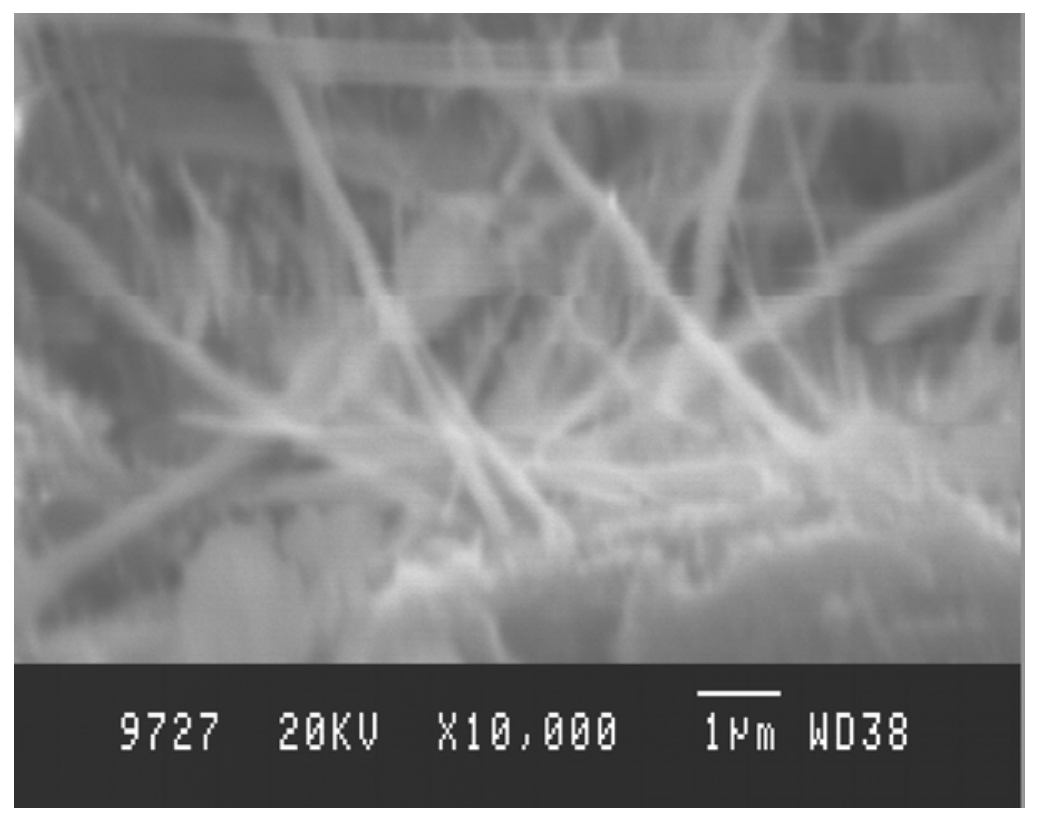

Figure 3. SEM micrograph of ettringite. 


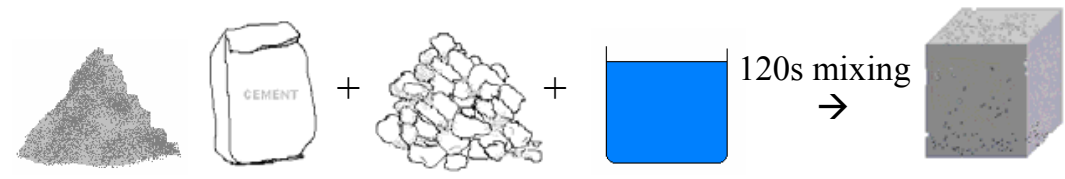

(i) NMA

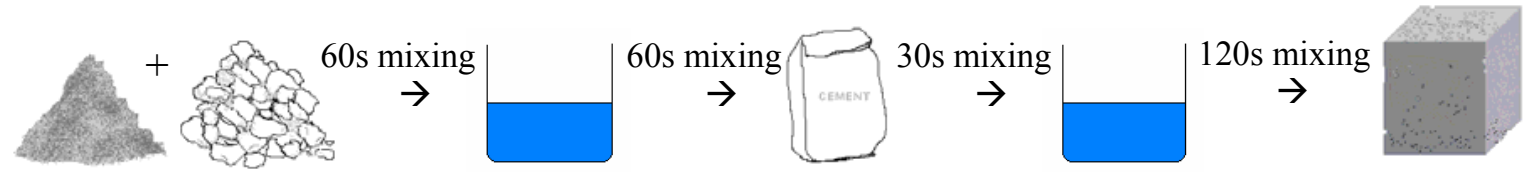

(ii) TSMA

Figure 4. Mixing procedures of the (i) Normal mixing approach and

(ii) Two-stage mixing approach 


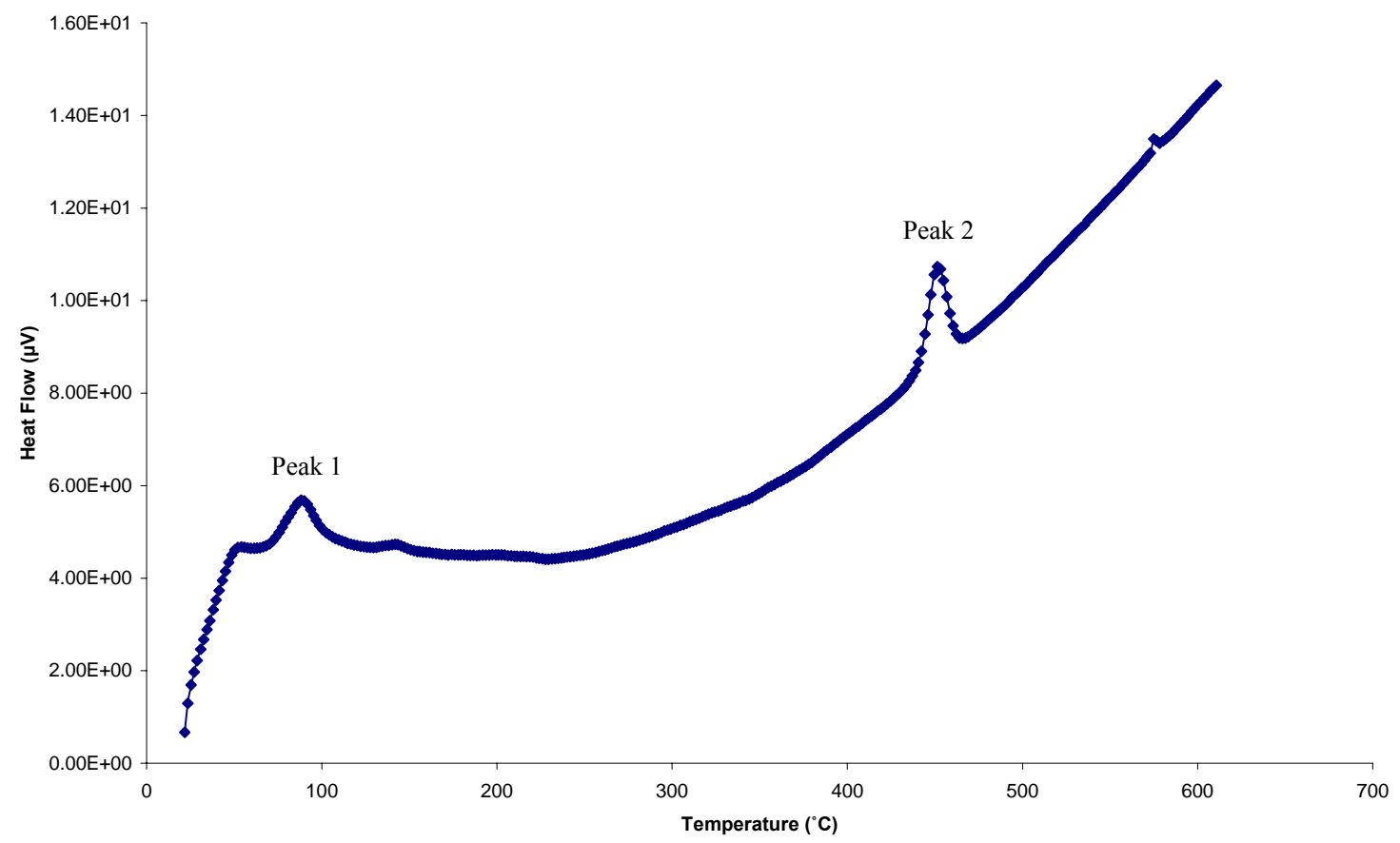

Figure 5. DSC curve for NMA with 0\% RA substitution in 28-day curing. 


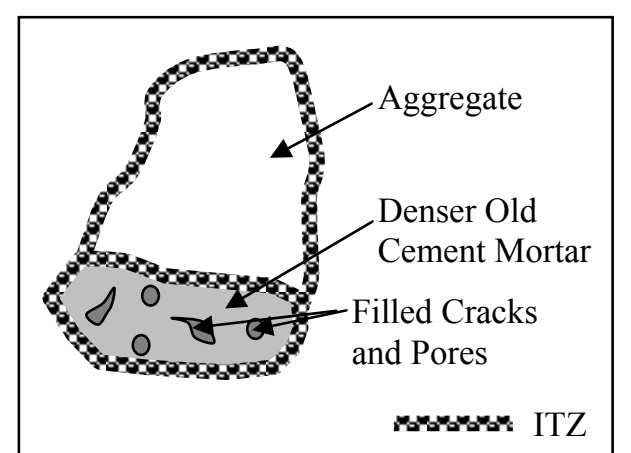

Figure 6. RA's structure after adopting TSMA. 


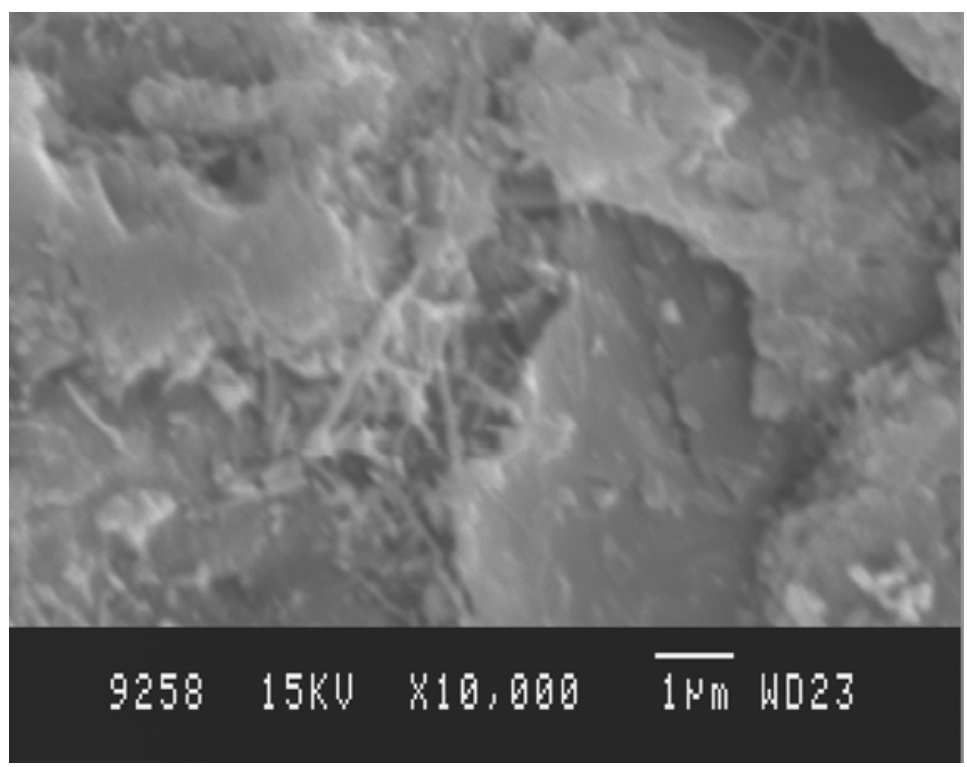

Figure 7. Crystallization of 20 percent RA substitution in TSMA. 


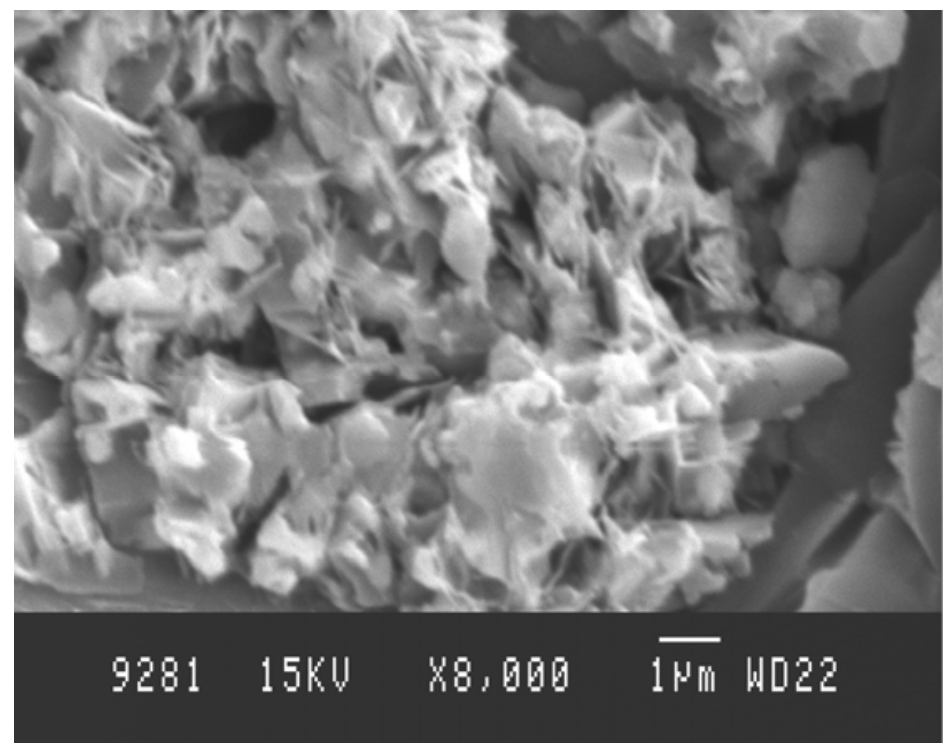

Figure 8. Crystallization of 20\% RA substitution in TSMA. 
Table 1. Symbols used for representing various materials.

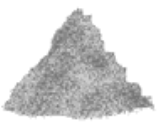

Fine Aggregate

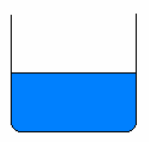

Half of the required Water

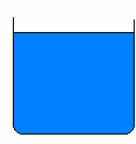

Water

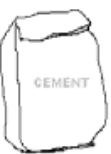

Cement

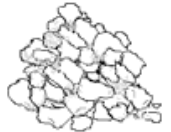

Recycled Aggregate + Natural Coarse aggregate

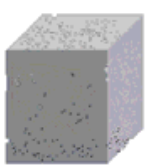

Concrete 
Table 2. Summary of endothermic peak and peak area of DSCs results.

\begin{tabular}{|c|c|c|c|c|c|c|}
\hline \multirow{2}{*}{$\begin{array}{c}\text { Curing } \\
\text { Condition (days) }\end{array}$} & \multicolumn{2}{|c|}{ Sample } & \multicolumn{2}{|c|}{$\mathrm{CSH}$} & \multicolumn{2}{|l|}{$\mathrm{CH}$} \\
\hline & Mixing Approach & RA Substitution (\%) & Endothermic Peak $\left({ }^{\circ} \mathrm{C}\right)$ & Peak Area $\left(\mu \mathrm{V}^{\circ} \mathrm{C}\right)$ & Endothermic Peak $\left({ }^{\circ} \mathrm{C}\right)$ & Peak Area $\left(\mu V^{\circ} \mathrm{C}\right)$ \\
\hline \multirow{6}{*}{28} & \multirow{3}{*}{ NMA } & 0 & 88.19 & 21.85 & 453.15 & 25.35 \\
\hline & & 20 & 88.21 & 18.38 & 446.14 & 25.30 \\
\hline & & 100 & 88.60 & 12.97 & 453.18 & 21.23 \\
\hline & \multirow{3}{*}{ TSMA } & 0 & 86.46 & 23.07 & 442.39 & 27.35 \\
\hline & & 20 & 93.48 & 34.21 & 446.01 & 48.31 \\
\hline & & 100 & 87.95 & 20.45 & 444.18 & 28.61 \\
\hline \multirow{6}{*}{56} & \multirow{3}{*}{ NMA } & 0 & 86.46 & 24.24 & 442.39 & 26.45 \\
\hline & & 20 & 87.95 & 15.85 & 447.70 & 18.96 \\
\hline & & 100 & 84.87 & 7.98 & 443.23 & 11.35 \\
\hline & \multirow{3}{*}{ TSMA } & 0 & 89.80 & 25.92 & 446.07 & 29.33 \\
\hline & & 20 & 95.50 & 25.44 & 447.69 & 44.59 \\
\hline & & 100 & 88.04 & 9.19 & 449.55 & 20.16 \\
\hline
\end{tabular}


Table 3. Summary of the results on compressive strength testing.

\begin{tabular}{|c|c|c|c|c|c|}
\hline \multicolumn{2}{|c|}{ Mixing Methods } & \multicolumn{2}{c|}{ NMA (days) } & \multicolumn{2}{c|}{ TSMA (days) } \\
\cline { 3 - 6 } & & 28 & 56 & 28 & 56 \\
\hline \multirow{2}{*}{ Compressive } & $0 \%$ & 55.7 & 67.6 & 56.0 & 68.0 \\
\cline { 2 - 6 } Strength (MPa) & $20 \%$ & 53.7 & 68.8 & 65.1 & 72.0 \\
\cline { 2 - 6 } & $100 \%$ & 48.3 & 52.7 & 55.6 & 69.6 \\
\hline
\end{tabular}

